Academic Platform Journal of Engineering and Science

\title{
Atriumlu Binalarda Duman Emiş Fanı Seçiminin Hesaplamalı Akışkanlar Dinamiği Yöntemi İle Belirlenmesi
}

\author{
${ }^{1}$ Gökhan COŞKUN, * ${ }^{2}$ Üsame DEMIR \\ ${ }^{1}$ Makine Mühendisliği Bölümü Sakarya Üniversitesi Turkey, gcoskun@ sakarya.edu.tr, \\ ${ }^{2}$ Makine Mühendisliği Bölümü Bingöl Üniversitesi Turkey, udemir@bingol.edu.tr, \\ Araștırma Makalesi \\ Geliș Tarihi: 20.04.2018 \\ Kabul Tarihi: 27.07.2018
}

Öz

Bu çalışmada Sakarya Üniversitesi Mühendislik Fakültesi M-3 Binasının zemin katında bulunan elektrik kat dağıtım panosunda ortaya çıkabilecek elektrik kaçağı veya aşırı yüklenme nedeniyle, fazla ısınan ana şalter ve plastik kabloların tutuşması sonucu ortaya çıkabilecek yangın modellenmiştir. Yangının modellenmesi için "Hesaplamalı Akışkanlar Dinamiği yazılımı olan "Fire Dynamic Simulator (FDS)" kullanılmıştır. Belirtilen nedenlerle oluşabilecek bir yangında dumanın ilerleyişi modellenerek can kayıplarını ortadan kaldıracak tedbirlerin tespit edilmesi ve gerekebilecek fiziki düzenlemelerin ortaya çıkarılması amaçlanmaktadır. İnsan kalabalığının fazla olduğu bir bina olması, binada kullanılan kabloların olası bir yangın esnasında aşırı derecede duman oluşturabilmesi ve binada duman tahliyesi için ters basınçlandırma sistemi uygulanamaması nedeniyle bu çalışmada öneri olarak atriumun çatı kısmında duman tahliye fanı eklenmesi düşünülmüş ve üç farklı duman tahliye debisi için analizler gerçekleştirilmiştir. Duman tahliye fanının kullanılması durumunda artan fan debisi ile birlikte duman yoğunluğunun önemli miktarda azaldı̆̆ tespit edilmiştir.

Anahtar kelimeler: Yangın Modelleme, Duman Emiş Fanı, FDS, Atrium Bina

\section{Determination Of Smoke Evacuation Fan Selection By Using Computational Fluid Dyamics For Atrium Building}

\author{
${ }^{1}$ Gökhan Coşkun, ${ }^{2, *}$ Usame Demir \\ ${ }^{1}$ Department of Mechanical Engineering, Sakarya University, Turkey, gcoskun@ sakarya.edu.tr \\ ${ }^{2}$ Department of Mechanical Engineering Bingol University Turkey, udemir@bingol.edu.tr
}

\begin{abstract}
In this study, a fire was modeled which could result in fire of overheated at main switch and plastic cables due to electrical leakage or overloading which may occur in the electric floor distribution panel located on the ground floor of the Sakarya University Engineering Faculty M-3 Building. A Computational Fluid Dynamic (CFD) software called Fire Dynamic Simulator (FDS) was used to model the fire. Fire smoke movement is modeled to identify the necessary precautions to prevent the loss of lives and to find out the necessary physical arrangements. It was considered as a suggestion to add a smoke exhaust fan on the roof of the atrium and the simulations was carried out for three different smoke evacuation fans in case that the cables used in the buildings could generate excessive smoke during a possible fire and the reverse pressurization system could not be applied for smoke evacuation in the building. From the simulation results in the case of using the smoke evacuation fan, it has been found that the smoke density decreases considerably with the increasing fan speed.
\end{abstract}

Keywords: Fire Modeling, Smoke Evacuation Fan, FDS, Atrium Building

\footnotetext{
*22Sorumlu yazar Adres: Mühendislik Mimarlık Fakültesi, Makine Mühendisliği Bölümü, Bingöl Üniversitesi, 12000, Bingöl TURKEY. Email adres: udemir@bingol.edu.tr, Telefon: +904262160012-1965
} 


\section{GÍRIŞ̧}

Yanma; 1s1, oksijen ve yanıc maddenin bir araya gelmesi ile meydana gelen kimyasal reaksiyondur. Yanmanın gerçekleşmesi için havanın içinde en az \%16 oksijen bulunması gerekmektedir. Oksijenin yanma gerçekleşen yerde \%16'nın altına inmesi durumunda yanma reaksiyonları azalır ve yavaş yavaş söner. Yangın kontrolsüz bir yanma olduğu için aynı durum yangın için de geçerlidir. Yanma ekzotermik bir olay olması nedeniyle yangın sonunda 1S1 açığa çıkarır. Bu 1sı yangın bölgesindeki yanıcı maddenin türüne cinsine göre farklılık göstermekle birlikte yangının büyüklüğüne doğrudan etkisi vardır. Yangının meydana gelmesindeki başlıca sebepleri ihmal, tedbirsiz davranış, korunma önlemlerinin alınmaması vb. gibi durumlarda oluşturur.

Özellikle bina yangınlarında ev ve ofis gibi alanlarda ahşap ve plastik ağırlıklı malzeme kullanımından kaynaklı olarak yangının ilerleme hızının çok yüksek olduğu bilinmektedir. $\mathrm{Bu}$ nedenle olası bir yangının en az mal ve can kayıpları ile atlatılabilmesi için ciddi önlemler alınması gerekmektedir. Yangında temel amaç duman oluşumuna müsaade edilmemesidir. Bunun için, tasarım aşamasında kullanılacak malzemeler yanmaya karşı dayanıklı veya insan sağlığını tehdit etmeyecek zararsız gaz yayan malzemelerden seçilmelidir. Bunun haricinde yapısal olarak bina mimarisi, kaçış güzergâhlarının belirlenmesi, yangın kompartımanlarının oluşturulması gibi önlemler alınmalıdır. Tüm bu tedbirlere rağmen çıkabilecek yangına karş1 ise dumanın yönlendirilmesi ve insanlara zarar vermeden tahliye yönlendirmelerinin dikkatli bir şekilde yapılması gerekir.

Özellikle alış-veriş merkezi, hastane, okul gibi yerlerde bina içerisinde yoğun insan bulunması herhangi bir yangın durumunda tahliyelerin izdiham oluşturmadan gerçekleştirilmesi çok önemlidir. Bu yüzden yoğun insan bulunan yerlerde kaçış alanlarının düzgün olması ve yangın esnasında kaçan insanların yangından dolayı oluşan dumandan etkilenmeden rahat bir şekilde tahliyesi gerekmektedir. Kaçış alanlarının dumandan daha az etkilenmesi için uygulanan yöntemlerin en sık kullanılanları ters basınçlandırma ve duman tahliye fanı ile dumanın dışarı atılmasıdır. Binanın yapısı ve tipine göre hangi yöntemin uygulanacağına karar verilir.

Yangın esnasında oluşan dumandan etkilenerek ölen insan sayısı için Türkiye'de istatistiksel anlamda bir çalışma olmadığı için rakamsal anlamda net olarak bir şey söylemek mümkün değildir. Amerika'da 2014 yılı içinde toplam 1.298.000 yangın çıkmış ve bu yangında 3.275 kişi hayatını kaybetmiş ve 15.775 kişi ise yaralanmıştır. Yapı ve araç yangınları ise tüm yangın olayları içerisinde \% 53 gibi bir rakamı oluşturmaktadır. $\mathrm{Bu}$ yangınlarda hayatını kaybedenlerin hepsi ise yapı ve araç yangınlarında meydana gelmiştir. Yapılarda meydana gelen yangınlarda elektrik kablolarından kaynaklanan yangınlar ise toplam bina yangınlarının yaklaşık \%10'unu oluşturmaktadır [1].
Yangın anında duman tahliyesini kolaylaştıracak havalandırma teknikleri üzerine yapılan çalışmalarda havalandırma sistemlerinin duman tahliyesine büyük bir katkıda bulunabileceği anlaşılmaktadır. Fang ve diğ. binalarda duman hareketi ve kontrolü üzerine yaptıkları çalışmada havalandırma sisteminin doğrudan duman yüksekliğini etkilediğini deneysel ve simülasyon yöntemlerle inceleyerek detaylandırmışlardır [2]. Doğal havalandırma yanında mekanik olarak zorlanmış hava akışı sağlayan duman tahliyesi sistemleri üzerine yaptıkları çalışmada Jie ve diğ. duman tahliyesi hızı ve havalandırma yüksekliğinin etkilerini deneysel olarak incelemişlerdir [3]. Elde ettikleri sonuçları kullanarak optimum havalandırma yüksekliğini ve hızını tespit etmeye çalışmışlardır.

Shen ve dig. 2003 yılında Tayvan'nın Taoyuan şehrinde bulunan 10 katlı, çok odalı ve birçok etkinlik ve eğlence salonu bulunan bir otelin 7. katında çıkan yangının gelişimini ve duman yayılımını incelemek için FDS yazılımı kullanılarak yangın simülasyonu yapmışlardır [4].

Oteldeki yangının etkileri ile simülasyon çalışması karşılaştırılmış ve çok benzer neticeler elde edilmiştir. A. Senveli ve diğ. yaptıkları çalışmada İstanbul'daki önemli bir ticaret merkezinin 8 katlı kapalı otoparkında jet fanlarla dumanın kontrolü için HAD (Hesaplamalı Akışkanlar Dinamiği) ile analizini yapmışlardır. Çalışma ile jet fanlarının konumunun ve seçiminin uygunluğunu HAD analizi ile çözümleyerek uygun metodu ekonomik ve işlevsel yolla elde etmişlerdir. Çalışmalarını yaparlarken Autodesk Simulation CFD programını kullanmışlardır [5].

$\mathrm{Bu}$ çalışmada Sakarya Üniversitesi Mühendislik Fakültesi M-3 binasında elektrik kablolarında oluşabilecek herhangi bir yangın durumunda bina içerisindeki duman dağılımı ve yangının nasıl ilerlediği incelenmiştir. M-3 binasında belirtilen sebeplerden dolayı yangın çıkma ihtimali en yüksek yer olan sunucu odasında ortaya çıkabilecek bir yangında, dumanın ilerleyişini izlemeyi, irdelemeyi ve bu sayede oluşturulacak kaçış planları ile olası can kayıplarını minimuma indirmek amaçlamaktadır. Ayrıca binada atrium kısmının çatı kısmında duman tahliye fanı eklenmesi durumunda içerideki duman yoğunlukları kıyaslanmıştır. Bina için en uygun tahliye fanı debisi seçimi gerçekleştirilmiştir.

\section{MODEL PARAMETRELERİ}

Sakarya Üniversitesi Mühendislik Fakültesi binalarından olan M-3 binasında çıkabilecek bir yangın senaryosu için öncelikle binanın 3 boyutlu CAD modeli oluşturulmuştur. HAD simülasyonunun yapılacağı ve M-3 binasını içeren bir çözüm hacmi belirlenmiştir. Sınırları belirlenen hacim üzerine HAD simülasyonunu yapabilmek için gereken ağ yapısı oluşturulmuştur. Hazırlanan modele ve yangının çıktığı ana şalter ve elektrik kablolarına sınır koşulları ve malzeme tanımlamaları girildikten sonra simülasyonlar gerçekleştirilmiştir. 


\subsection{Boyutlu CAD Modelinin Hazırlanması}

Mimari projesi mevcut olan Mühendislik Fakültesi M-3 binasının detaylı ölçüleri teknik resim üzerinden alınmıştır. PyroSim programinda binanın 3 boyutlu modeli oluşturulmuştur. Şekil 1'de 3 boyutlu modelin görseli, Şekil 2'de ise yangının çıktığı zemin katın 2 boyutlu görseli verilmiştir. Bina 3 katlıdır, toplam 21 adet sınıf, 6 adet wc mahalli, 5 adet diğer mahaller (depo, temizlik vb.) ve 1 adet konferans mahallinden oluşmaktadır. Binanın orta kısmında atrium bulunmakta ve çatı ile birleşmektedir.

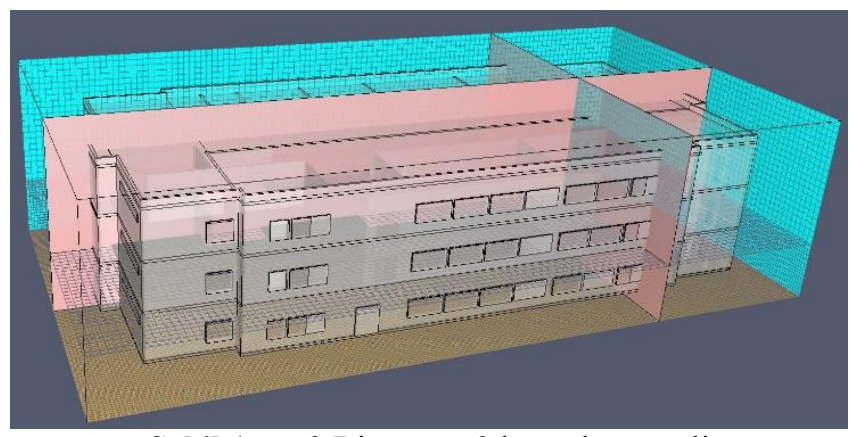

Şekil 1. M-3 Binasının 3 boyutlu görseli

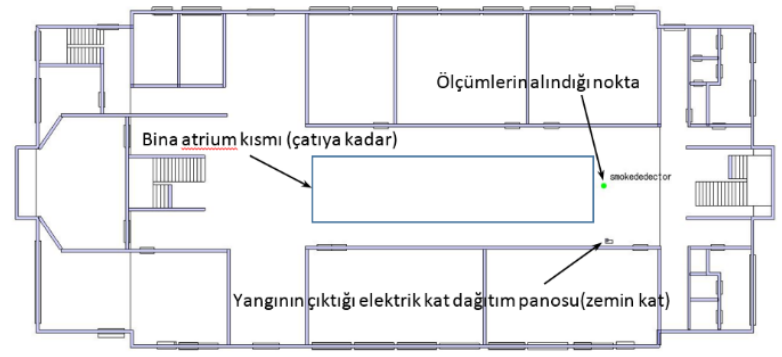

Şekil 2. M-3 Binasında zemin katın 2 boyutlu görseli

Bina 4 farklı durumda simülasyonu yapılacak şekilde modellenmiştir. Bu durumlar şunlardır:

- Fan bölgelerinde doğal havalandırmanın kullanıldığı durum (fansız)

- $\quad 3$ adet fan ile atrium açıklığından $15 \mathrm{~m} 3$ /s 'lik duman tahliyesinin yapıldı $\breve{g} 1$ durum

- $\quad 3$ adet fan ile atrium açıklığından $30 \mathrm{~m} 3$ /s 'lik duman tahliyesinin yapıldı $\breve{g} 1$ durum

- $\quad 3$ adet fan ile atrium açıklığından $45 \mathrm{~m} 3$ /s 'lik duman tahliyesinin yapıldığ durum

Fanın kullanıldığı senaryoda piyasada bulunabilen dikey emişli 5 m3/sn'lik, 10 m3/sn'lik ve 15 m3/sn'lik yüksek emiş debisine sahip olan 3 adet fan seçilerek modele eklenmiştir. Fan şekil 2'de çizgisel sensörün olduğu noktaya eklenen duman sensörünün dumanı algılaması ile devreye girecek şekilde modelde uygulanmıştır.

Senaryolara göre düzenlenen CAD modelleri STL formatında yazılıma aktarılmıştır. Şekil 3'de farklı senaryolar için hazırlanan ve yazılıma aktarılan CAD modeli görülmektedir.

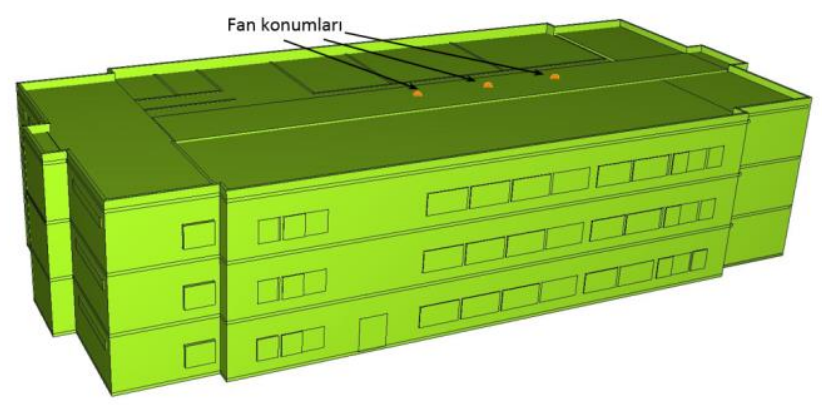

Şekil 3. Senaryolar için hazırlanan CAD modelinde fan konumlarının gösterimi

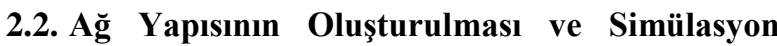 Parametreleri}

PyroSim programı açık kaynak kodlu FDS yazılımını içerisinde barındırmakta ve bu yazılım arka planda HAD çözücüsü olarak çalışmaktadır. FDS temelde yangın modellerini oluşturmak için hazırlanmış bir yazılımdır. Ara yüz olarak çalışan PyroSim yazılımı ile 3 boyutlu modeller oluşturup, yangın, reaksiyon ve malzeme özellikleri tanımlanıp ve yangın analizi entegreli paralel çözümler yapılabilir. Şekil 4'de modelin ağ yapısı verilmiştir ve ağ yapısı oluşturulan hacimlerin dış sınırları siyah çizgiler ile belirtilmiştir. HAD yazılımda akış çözümü LES türbülans modeli ile yapıldığı için yazılım otomatik olarak akış hacmini katı modelden ayırarak bu hacme düzenli (dörtgensel) ağ yapısı oluşturmaktadır. Yazılımın dörtgensel ağ yapısını kullanmasının temel nedeni türbülans modelinin LES olarak uygulanması ve LES türbülans modelinin düzenli ve oldukça yoğun ağ yapısına ihtiyaç duymasıdır. Bu yüzden modeldeki kıvrımlı yüzeyler ağ yapısının büyüklüğüne göre dörtgenlere bölünmektedir.

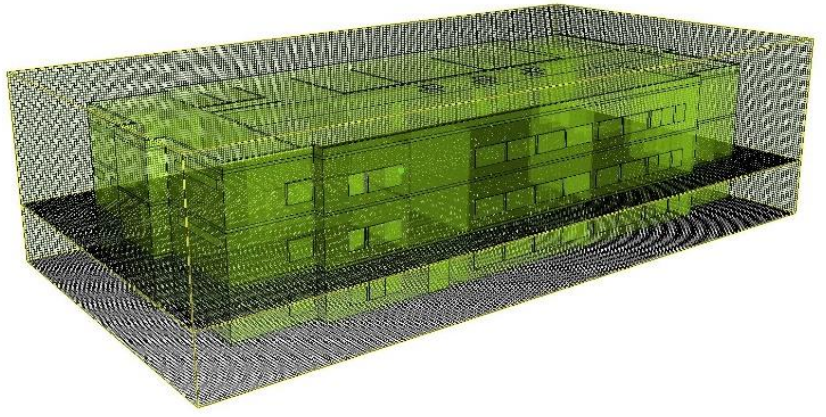

Şekil 4. Oluşturulan ağ yapısı ve dış sınırları

\section{3. İdeal Ağ Sayısı Hesabı}

Çalışmada ăg sayılarının düzgün seçilmesi sonuçların kalitesi açısından önem arz etmektedir. FDS'deki en önemli sayısal parametre 1zgaralı hücre boyutudur. HAD modelleri, sayısal bir grid üzerinde kütle, momentum ve enerjinin korunum denklemlerinin yaklaşık bir formunu çözer. Bu sebeple ağ sayısı hesabı yapılırken FDS ağ sayısı hesaplama modülü ile gerekli ağ büyüklükleri hesaplatılmıştır [6]. Kullanılan ağ sayısı değerleri farkı analizlerde arttırıldığında kayda değer değişiklikler olmadığı görülmüştür. Bu sayede 
model ağ yapısının çözüme etkilerinden bağımsız hale geldiğinden emin olunmuştur. Bu sebeple tüm simülasyonlar $0,21 \times 0,21 \times 0,21[\mathrm{~m}]$ ölçülerinde eş dörtgen prizmalardan oluşan 2.677.350 adet ağa sahip hacimsel yapı kullanılarak yapılmıştır. FDS kullanım kılavuzunda [7], çeşitli senaryolardaki yangınları doğru bir şekilde çözmek için 4 ile 16 arasında bir $\mathrm{D} * / \mathrm{dx}$ oranı kullanılmıştır. Çalışmada $\mathrm{D} *$ / dx değeri 4 alınarak çözümlemeler yapılmıştır. Bu değerin farklı alındığg durumda gözle görülür değişiklikler olmadığı analizlerle kontrol edildi. Yükselen duman içeren simülasyonlar için, akış alanının ne kadar iyi çözüldüğünün ölçüsü boyutsuz bir ifadeyle hesaplanır. Bu hesaplamalar aşağıdaki boyutsuz formülle (formülde mevcut çalışma için atanmış uygun değerler kullanılmıştır) yapılabilmektedir [8].

$$
\begin{aligned}
& D^{*}=\left(\frac{\dot{Q}}{\rho_{\infty} c_{p} T_{\infty} \sqrt{g}}\right)^{\frac{2}{5}} \\
& D^{*} / d x=4
\end{aligned}
$$

Burada; Q= HRR = Isıl Yay1lım Oran $1(\mathrm{~kW})=750 \mathrm{~kW}, \rho_{\infty}=$ Yoğunluk $\left(\mathrm{kg} / \mathrm{m}^{3}\right)=1,204, \mathrm{c}_{\mathrm{p}}=$ özgül 1s1 $(\mathrm{kJ} / \mathrm{kg}-\mathrm{K})=$ $1,005, \mathrm{~T}_{\infty}=$ sicaklık $(\mathrm{K})=293 \mathrm{~K}$ ve $\mathrm{g}=$ yer çekim ivmesi $(\mathrm{m} /$ $\left.\mathrm{s}^{2}\right)=9,81$ olarak alınmıştır.

Gerekli hesaplamalar yapıldı ğında

$\mathrm{D}^{*}=$ karakteristik yangın çap $1(\mathrm{~m})=0,855 \mathrm{~m}$ olarak bulunur.

$\mathrm{D} * / \mathrm{dx}=4$ olduğundan;

$\mathrm{dx}=\mathrm{ağ}$ ölçüsü $(\mathrm{m})=0,21 \mathrm{~m}$ olarak kullanıld1.

A $\breve{g}$ hacmi/ağ ölçüsü = toplam ağ sayısı

$57 \times 29 \times 15 / 0,21 \times 0,21 \times 0,21=2677350$ adet ağ sayısına göre analiz yapılmıştır.

\subsection{Simülasyon Parametreleri}

Zemin katta koridorda yer alan elektrik kat dağıtım panosu ve kablo kanalları Şekil 5'de görülen koridorda bulunduğu şekilde ve boyutlarında çizilerek modele eklenmiştir. Yangının kat panosunda çıkabileceği ihtimali daha yüksek olduğundan yangının başlangıç yeri de yine kat dağıtım panosunun ön kısmı olarak tanımlanmıştır.

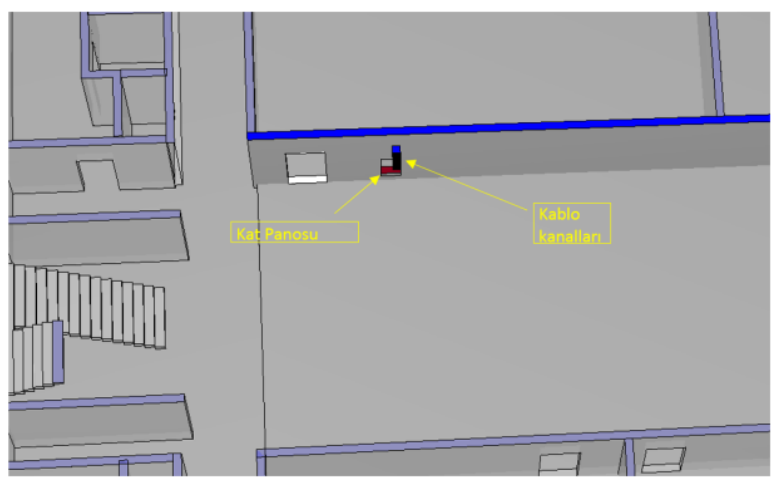

Şekil 5. Zemin katta kat panosu ve kablo kanallarının konumları
M-3 binasının duvarları modelde beton malzeme olarak tanımlanmıştır. Zemin katta yer alan elektrik panosu için PVC kablo malzemesi tanımlanmıştır. Tanımlanan malzemelerin yoğunluk, özgül ısı, iletkenlik ve 1şınım yayma faktörü değerleri Tablo 1'de görülmektedir.

\begin{tabular}{|c|c|c|c|}
\hline \multicolumn{4}{|c|}{ Malzeme Özellikleri } \\
\hline Malzeme & Beton & Çelik & $\begin{array}{l}\text { Kablo } \\
\text { (PVC) }\end{array}$ \\
\hline Yoğunluk & $\begin{array}{c}2280 \\
\mathrm{~kg} / \mathrm{m}^{3}\end{array}$ & $\begin{array}{c}7850 \\
\mathrm{~kg} / \mathrm{m}^{3}\end{array}$ & $\begin{array}{c}1380 \\
\mathrm{~kg} / \mathrm{m}^{3}\end{array}$ \\
\hline Özgül Isı & $\begin{array}{c}1,04 \\
\mathrm{kj} /(\mathrm{kg} . \mathrm{K})\end{array}$ & $\begin{array}{c}0,46 \\
\mathrm{kj} /(\mathrm{kg} . \mathrm{K})\end{array}$ & $\begin{array}{c}1,289 \\
\mathrm{kj} /(\mathrm{kg} . \mathrm{K})\end{array}$ \\
\hline İletkenlik & $\begin{array}{c}1,8 \\
\mathrm{~W} /(\mathrm{m} \cdot \mathrm{K})\end{array}$ & $\begin{array}{c}45,8 \\
\mathrm{~W} /(\mathrm{m} . \mathrm{K})\end{array}$ & $\begin{array}{c}0,192 \\
\mathrm{~W} /(\mathrm{m} . \mathrm{K})\end{array}$ \\
\hline $\begin{array}{l}\text { Işınım Yayım } \\
\text { Faktörü }\end{array}$ & 0,9 & 0,95 & 0,9 \\
\hline
\end{tabular}

Tablo 1. Malzeme Özellikleri

Zamana bağlı olarak simülasyonun yapılacağı çalışmada kurgulanan yangın için model 1000 saniye süresince çalıştırılmış ve bu süre zarfında dumanın bina içerisindeki yayılımı incelenmiştir.

Sakarya ilinin günlük ortalama nem oranının yaklaşık \%70 olduğu tespit edilmiş, yangın esnasından nem oranı $\% 70$ olacak şekilde modele girilmiştir [9]. Modelde kullanılan diğer simülasyon parametreleri Tablo 2'de verilmiştir.

Tablo 2. Ortam parametreleri (Environment Parameters)

\begin{tabular}{|l|l|}
\hline Ortam Sıcaklığı & $20{ }^{\circ} \mathrm{C}$ \\
\hline Ortam Basıncı & $1 \mathrm{~atm}$ \\
\hline Oksijenin kütle oranı & $0,232378 \mathrm{~kg} / \mathrm{kg}$ \\
\hline Maksimum Görünürlük & $30 \mathrm{~m}$ \\
\hline Yer Çekimi İvmesi & $9,81 \mathrm{~m} / \mathrm{s}^{2}$ \\
\hline
\end{tabular}

\section{SIMMULASYON SONUÇLARI}

Her bir senaryo için 1000 saniye boyunca çalıştırılan simülasyonların sonucunda bina içerisindeki duman dağılımı ve hava hızlarının zamana bağlı değişimlerinin 200, 400, 600, 800 ve 1000 saniye sonraki durumları görsel olarak elde edilmiştir. Ayrıca bina içerisindeki ortalama 1sı yayılım oranı da yine zamana bağlı olarak bir grafikte verilmiştir.

\subsection{Farklı Senaryolar İçin Bina İçerisindeki Duman Dağılımının İncelenmesi}

Yapılan simülasyonlar sonucunda elde edilen verilere göre M-3 binasının zemin katta kat dağıtım panosunda çıkacak yangının neticesinde bina içerisinde dumanın yangın başlangıcından 200 saniye sonraki durumu Şekil 6'da görülmektedir. Buna göre tüm senaryolarda duman yukarı yönde atrium boşluğunda binanın son katındaki 1 şıklık penceresine ilerlemeye başlamıştır.

Senaryo 1 haricinde eklenen duman detektörüne 152. saniyede duman ulaşmaktadır ve böylece detektörün gönderdiği sinyal ile fan aktif hale gelmiştir. 
152. Saniyeden sonra fanlar sürekli olarak çalışmış ve senaryolara göre sirasiyla saniyede $15 \mathrm{~m}^{3}, 30 \mathrm{~m}^{3}$ ve $45 \mathrm{~m}^{3}$ havayı binadan dişarı tahliye etmiştir. 200. saniyede fanın kullanıldığ 1 diğer senaryolarda dumanın diğerlerine göre daha az ilerlediği görülmektedir.

$\mathrm{Bu}$ durumun fanın bina içerisinden dış ortama sürekli hava pompalayarak hava sirkülasyonunu arttırdığ ve koyu duman oluşumunu azalttığı düşünülmektedir.
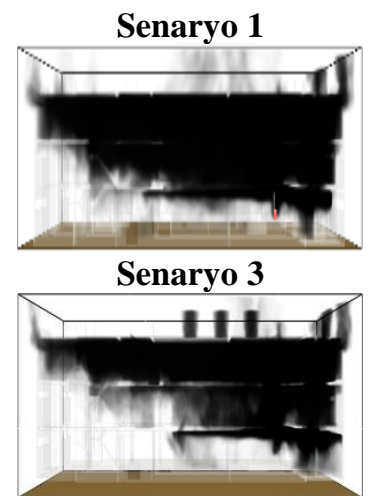

Şekil 6. 200’üncü Saniyedeki Dumanın Bina İçerisindeki Dağılımı

Şekil 7'de 400'üncü saniyede senaryo 1'de 2.katta ve 3.katta duman yoğunluğunun koyulaştı̆̆ı görülmektedir. 152. Saniyeden sonra fanlar sürekli olarak çalışmış ve senaryolara göre fan debisinin artması ile koyu duman oluşumunun azaldığı görülmektedir.
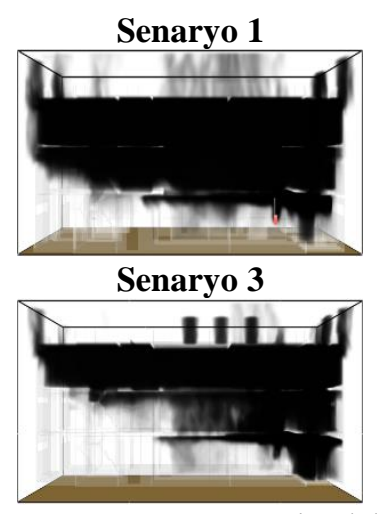

Şekil 7. 400’üncü Saniyedeki Dumanın Bina İçerisindeki Dağılımı

Şekil 8'de 600'üncü saniyede senaryo 1'de dumanın çatı kısmında birikmesi ile duman yoğunluğunun alt katlara doğru ilerlediği görülmektedir. Diğer senaryolarda 152.

Saniyeden sonra fanlar sürekli olarak çalışmış elektrik panosundan duman çıkışı devam etmesine rağmen koyulaşma senaryo 1'e göre daha az olduğu görülmektedir.
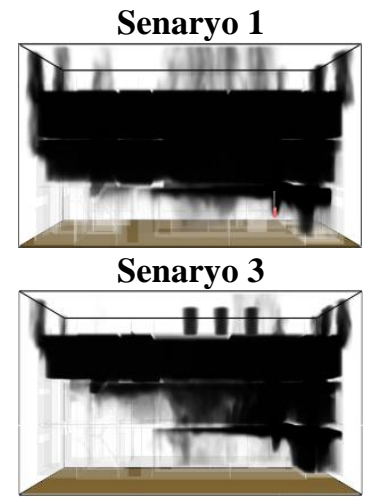

Şekil 8. 600'üncü Saniyedeki Dumanın Bina İçerisindeki Dağılımı

Şekil 9'da 800'inci saniyede senaryo 1'de duman yoğunluğunun 2. ve 3.katta artık kaçışa engel olacağ düşünülmektedir. Yangın yaklaşık 16 dakikadır sürmesine rağmen diğer senaryolarda da görüldüğü gibi tahliye fanlarıyla kaçışa daha uygun ortam oluştuğu anlaşılmaktadır.
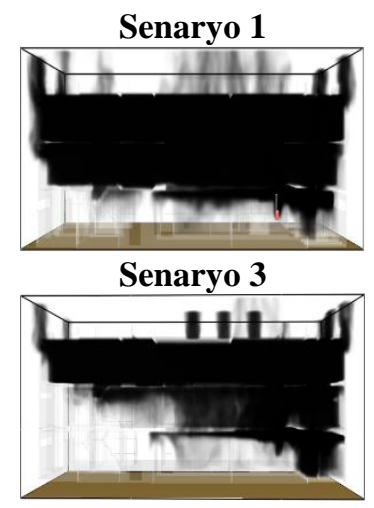

Senaryo 2

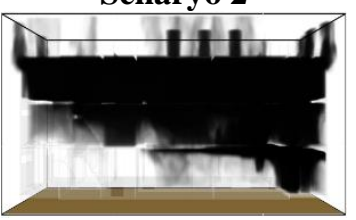

Senaryo 4

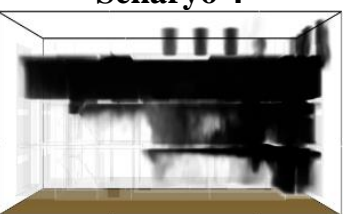




\subsection{Farklı Senaryolar İçin Bina İçerisindeki Gazların Akış Hızının İncelenmesi}

Dört senaryo için yangının başlangıcından itibaren bina içerisindeki gazların akış hızlarının dağılımı binayı dik kesen 2 boyutlu bir yüzey üzerinden alınan kesit görüntüsü ile verilmiştir. Şekil 11'de görüldüğü üzere yangının çıktığ 1 koridordan alınan kesit görünümünü kapsamaktadır. Belirtilen kesitteki gazların hareketlerinin yangının ve dumanın bina içerisinde dağılımının irdelenmesi açısından önemli olduğu düşünülmektedir.

Bina içerisindeki gazların akış hızı verileri simülasyonda tanımlandığ 1 şekliyle havayı oluşturan O2 ve N2'nin yanında dumanın hızını da temsil etmektedir. Fan hızları farklı olduğu için verilerin alındığı kesitler için verilen hız skalaları farklılık göstermektedir bu sebeple verileri değerlendirirken skala değerlerine dikkat edilmesi gerekmektedir.

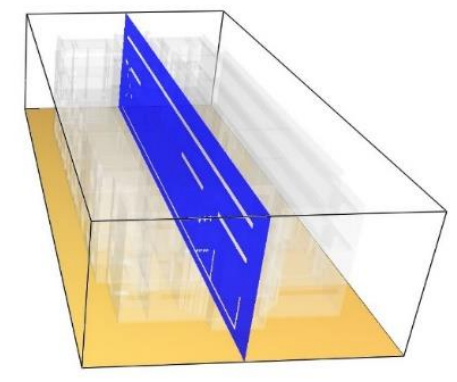

Şekil 11. Bina içerisi gazların akış hızı dağılımının alındığ kesit görüntüsü

Şekil 12'de gaz detektörünün 152. Saniyede dumanı algılaması sonucu fanlar devreye girmiştir. 200'üncü saniye için gazların hızının zemin katlarda ve zemin katların tavanlarında artmaya başladığı görülmektedir. Fan debilerine bağlı olarak duman atış hızlarının fan çıkışlarında en yüksek seviyede olduğu görülmektedir.

\section{Senaryo 1}

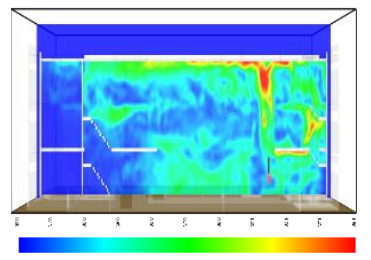

Senaryo 3

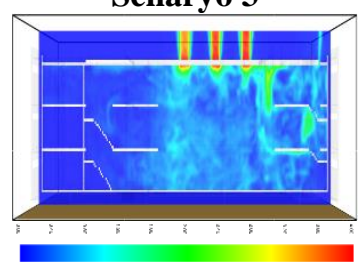

Şekil 12. 200 saniye sonra bina içerisindeki gazların akış hızı dağılımı

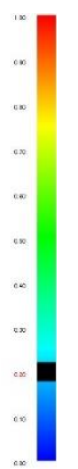

Şekil 13'de dumanın fanlarla tahliyesinin hızla devam ettiği yükselen dumanın atrium boşluğundan fanlara doğru ilerlediği görülmektedir.
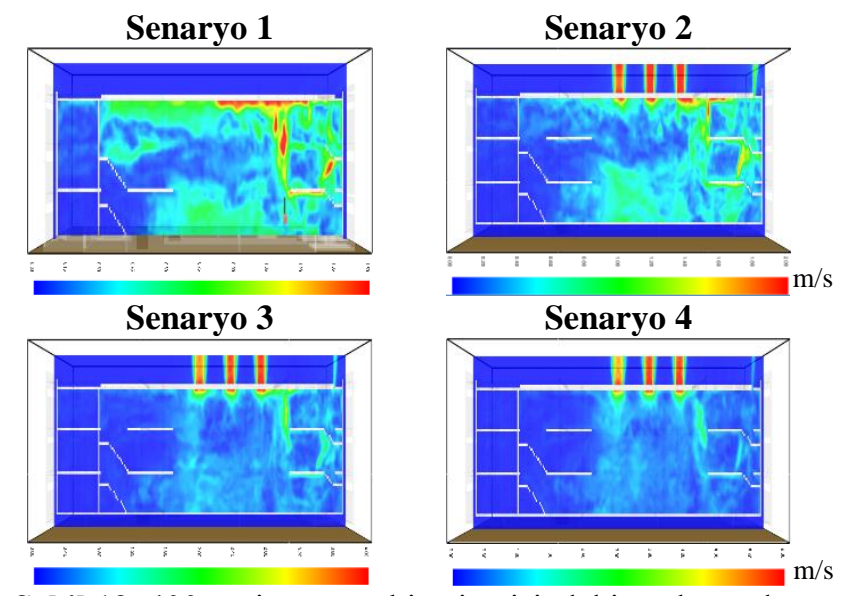

Şekil 13. 400 saniye sonra bina içerisindeki gazların akış hızı dağılımı
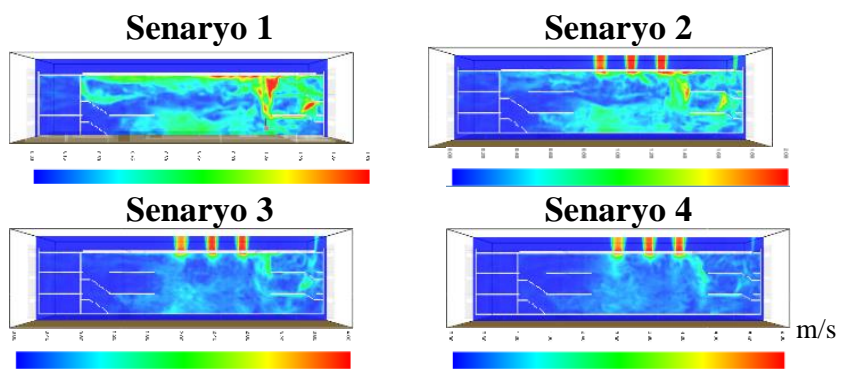

Şekil 14. 600 saniye sonra bina içerisindeki gazların akış hızı dağılımı
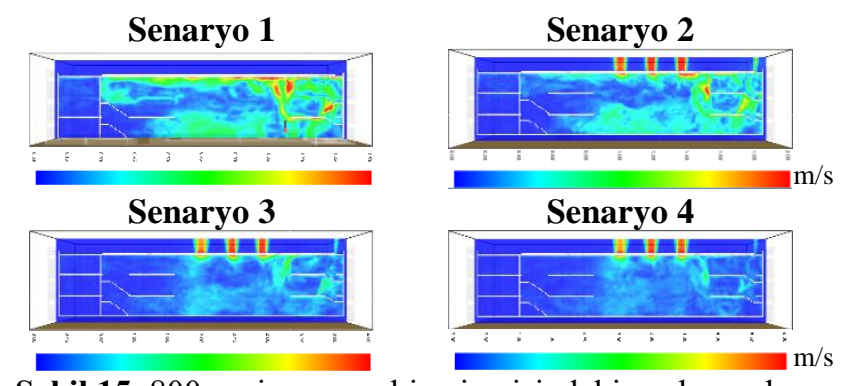

Şekil 15. 800 saniye sonra bina içerisindeki gazların akış hızı dağılımı
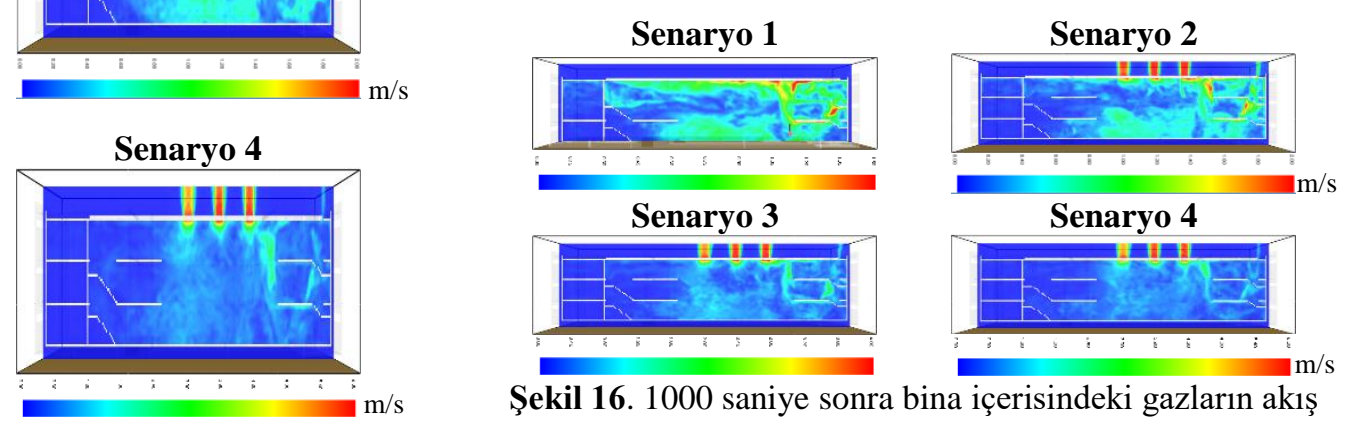

Şekil 16. 1000 saniye sonra bina içerisindeki gazların akış hızı dağılımı 


\section{SONUÇ VE DEĞERLENDİRME}

Bu çalışmada binada fan olmadığı durum, 3 adet $5 \mathrm{~m}^{3} / \mathrm{sn}^{\prime}$ 'lik fanlı durum, 3 adet $10 \mathrm{~m}^{3} / \mathrm{sn}^{\prime}$ lik fanlı durum ve 3 adet 15 $\mathrm{m}^{3} / \mathrm{sn}$ 'lik fanlı duruma göre tasarlanan dört farklı senaryo için yangın simülasyonları yapılmıştır. Yapılan simülasyonlar ile yangın dumanının bina içerisindeki dağılımı ve gaz hızları farklı senaryolara göre elde edilerek sonuçlar incelenmiştir. Elde edilen verilere göre sonuçlar maddeler halinde sıralanırsa;

- Yapılan analiz sonuçları için fan kullanılmaması durumunda (senaryo 1) binada çıkacak bir yangın sonucunda tüm katları kısa süre içerisinde dumanların kapladığı, bu durumun kaçışı zorlaştırdığı ve yangına müdahale şansı vermediği anlaşılmaktadır. $\mathrm{Bu}$ durum yangında can kayıplarının ilk dakikalarda ve zehirlenmelerden meydana geldiği düşünülürse önlem alınması gereken bir durumdur.

- Binanın orta kısmı atrium olduğundan fan uygulamasina olanak vermektedir. $\mathrm{Bu}$ durumda uyguladığımız 3 adet fan ile duman binadan daha aktif bir şekilde tahliye edilebilecek ve itfaiye ekiplerinin müdahalesine daha rahat imkan sağlayabilecektir.

- $\quad$ Fan debisinin en yüksek olduğu senaryo 4'de duman tahliyesinin de artarak kaçış yollarında duman yoğunluğunu ve can kaybı riskini azalttığı anlaşılmaktadır.

- Simülasyonlar neticesinde düşük debili fan kullanılması durumunda (senaryo 2 ve 3 ) merdiven alanlarında duman yoğunluğunun daha fazla olduğu gözlemlenmiştir. İnsan tahliyesinin gerçekleştiği merdivenlerde duman birikiminin olması istenmeyen bir durumdur. Merdiven çıkışlarına kapılar konulup alanların dumandan arındırılması veya tahliye merdivenlerinin olduğu alanın çatı bölgesine ek bir duman tahliye fanının bağlanması ile insan tahliyesinin daha emniyetli olabileceği anlaşılmaktadır.

- $\quad$ Çıkan yangın büyüklüğü ve duman miktarı farklı değişkenlere bağlıdır. Bu sebeple fan seçiminin binaya ve yangın yüküne göre oldukça spesifik bir konu durumuna geleceğinden kamuya açık her yapı için simülasyonların uygulanması ve buna göre doğru kapasitede fan seçiminin yapılması gerektiği önerilmektedir.

\section{TEŞEKKÜR}

$\mathrm{Bu}$ çalışma, Sakarya Üniversitesi Bap birimi tarafından 2017-01-06-026 nolu proje kapsamında desteklenmiștir.

\section{KAYNAKÇA}

[1].NFPA, URL: $\quad$ http://www.nfpa.org/news-andresearch/fire-statistics-and-reports/fire-statistics (Erişim zamanı; Şubat, 8, 2017).

[2].L. Fang, P. V. Nielsen and H. Brohus, "Investigation on smoke movement and smoke control for atrium in green and sustainable buildings", Aalborg University, Department of Civil Engineering Technical Report No. 32, 2007.

[3].J. Jie, L. Kaiyuan, Z. Wei, H. Ran, "Experimental investigation on influence of smoke venting velocity and vent height on mechanical smoke exhaust efficiency", Journal of Hazardous Materials, vol. 177, Sayı 1-3, pp. 209215, 2010.

[4].T-S. Shen, Y-H. Huang, S.-W. Chien, "Using fire dynamic simulation (FDS) to reconstruct an arson fire scene", Building and Environment, vol. 43, pp. 1036-1045, 2008.

[5].A. Senveli, T. Dizman, A. Celen, D. Bilge, A. S. Dalkılıç, S. Wongwises; "CFD Analysis of Smoke and Temperature Control System of an Indoor Parking Lot with Jet Fans", Journal of Thermal Engineering, Vol.1 iss.2, 2015.

[6].FDS Mesh Size Calculator, URL: https://www.utfireresearch.com/fds-mesh (Erişim zamanı; Ocak, 15, 2017).

[7].Nükleer Güç Santralı Uygulamalarında Seçilen Yangın Modellerinin Doğrulanması ve Onaylanması NUREG 1824, ABD Nükleer Düzenleme Komisyonu, 2007

[8].NIST Special Publication 1019 Sixth Edition Fire Dynamics Simulator User's Guide Kevin McGrattan Simo Hostikka Randall McDermott Jason Floyd Craig Weinschenk Kristopher Overholt.

[9].Seçilmiş Göstergelerle Sakarya 2013, Türkiye İstatistik Kurumu. Yayın No: 4218 ISSN: 1307-0894. 